\title{
Safety of edoxaban, an oral factor Xa inhibitor, in Asian patients with non-valvular atrial fibrillation
}

\author{
Namsik Chung ${ }^{1}$; Hui-Kyung Jeon²; Li-Ming Lien³; Wen-Ter Lai4; Hung-Fat Tse ${ }^{5}$; Wook-Sung Chung ${ }^{6}$; Tsong-Hai Lee ${ }^{7}$; Shih-Ann Chen ${ }^{8}$
}

${ }^{1}$ Severance Hospital, Yonsei University College of Medicine No. 134, Sinchon-dong, Seodaemun-gu, Seoul, Korea; ${ }^{2}$ Uijeongbu St. Mary's Hospital, Catholic University of Korea No. 65-1, Kumoh-dong, Uijeongbu City, Kyungki-do, Korea; ${ }^{3}$ Shin Kong Wu Ho-Su Memorial Hospital No. 95, Shihlin District, Taipei, Taiwan; ${ }^{4}$ Chung-Ho Memorial Hospital, Kaohsiung Medical University No.100, Kaohsiung, Taiwan; ${ }^{5}$ Queen Mary Hospital No. 102, Hong Kong, China; ${ }^{6}$ St. Mary's Hospital No. 62, Yeouido-dong, Yeongdeungpo-gu, Seoul, Korea; ${ }^{7}$ Chang Gung Memorial Hospital - Linko No. 5, Kuei Shan, Taoyuan, Taiwan; ${ }^{8}$ Taipei Veterans General Hospital No. 201, Sec. 2, Taipei 112, Taiwan

\begin{abstract}
Summary
Edoxaban is an oral, reversible, direct factor Xa inhibitor in phase III clinical development for the prevention of stroke in atrial fibrillation (AF). A phase II study was undertaken to evaluate the safety and efficacy of edoxaban in Asian patients with non-valvular AF with $\mathrm{CHADS}_{2}$ score $\geq 1$. In a multicentre, active-controlled, double-blind edoxaban and open-label warfarin, parallel-group study, a total of 235 patients from four Asian countries were randomly assigned to edoxaban $30 \mathrm{mg}$ $\mathrm{qd}, 60 \mathrm{mg}$ qd or warfarin dose adjusted to international normalised ratio of 2-3 for three months. The primary endpoint was the incidence of centrally adjudicated all bleeding events (major, clinically relevant non-major and minor). Secondary endpoints included thromboembolic events, biomarkers of thrombus formation and all adverse events (AEs). The incidence of all bleeding events $(95 \% \mathrm{CI})$ was $20.3 \%(12.9,30.4)$ for edoxaban $30 \mathrm{mg}, 23.8 \%(15.8,34.1)$ for edoxaban $60 \mathrm{mg}$, and
\end{abstract}

$29.3 \%(20.2,40.4)$ for warfarin. A subgroup analysis suggested low body weight $(\leq 60 \mathrm{~kg})$ may affect the incidence of bleeding events with edoxaban. The incidence of study drug-related AEs was $22 \%$ for edoxaban $30 \mathrm{mg}, 29 \%$ for edoxaban $60 \mathrm{mg}$ and $33 \%$ for warfarin. No thromboembolic events occurred in any treatment group. In conclusion, this phase II study found a trend for a reduction in the incidence of all bleeding events in Asian AF patients with edoxaban $30 \mathrm{mg}$ and $60 \mathrm{mg}$ compared with warfarin. Adverse events were similar between the edoxaban 60-mg and warfarin groups and were lower with the edoxaban 30-mg group.

\section{Keywords}

Edoxaban, non-valvular atrial fibrillation, factor Xa inhibitor, anticoagulant, warfarin

\author{
Correspondence to: \\ Namsik Chung \\ Severance Hospital, Yonsei University College of Medicine \\ 250 Seongsanno, Seodaemun-gu, Seoul 120-752, Korea \\ Tel.: +82 22228 2000, Fax: +82 23125370 \\ E-mail: namsikc@yuhs.ac
}

ClinicalTrials.gov number: NCT00806624
Financial support:

This study was funded by Daiichi Sankyo Co., Ltd., Tokyo, Japan.

Received: July 15, 2010

Accepted after major revision: November 18, 2010

Prepublished online: December 6, 2010

doi:10.1160/TH10-07-0451

Thromb Haemost 2010; 105: 535-545

\section{Introduction}

Atrial fibrillation (AF), the most common cardiac arrhythmia, is increasing in prevalence as the population ages $(1,2)$. AF is associated with considerable morbidity and mortality, and is a strong independent risk factor for stroke $(1,3)$. The rate of ischaemic stroke among patients with non-valvular AF (NVAF) averages 5\% per year, three to seven times the rate among people without $\mathrm{AF}(4,5)$. Although clinical trials and meta-analyses have shown that anticoagulation with vitamin K antagonists (VKAs) is the most effective way to reduce the risk of stroke $(5,6)$, about half of all eligible patients do not receive anticoagulation therapy (7-12). Studies suggest that the underuse of VKAs is due to several factors including the risk of bleeding; drug-drug, drug-food and alcohol interactions and the need for dose titration, laboratory monitoring and dose adjustment $(13,14)$. Major bleeding rates range from 0.6 to $2.5 \%$ in well-controlled primary prevention trials with VKAs (15). New approaches to anticoagulation for stroke prevention in patients with AF are being studied. Direct factor Xa (FXa) inhibitors are a promising new class of anticoagulants because of the role of FXa being located at the intersection of the intrinsic and extrinsic pathways of the coagulation system.

Edoxaban is an oral, direct FXa inhibitor in phase III development for the prevention of stroke in patients with AF and for the treatment of venous thromboembolism. It has good oral bioavailability with rapid absorption and a median time of maximum observed plasma concentration $\left(t_{\max }\right)$ of 1-2 hours (h). Edoxaban demonstrated predictable and linear pharmacokinetics $(\mathrm{PK})$ in doses up to $120 \mathrm{mg}$ without saturable absorption (16). It is not extensively metabolised by CYP3A, giving edoxaban limited risk of drug-drug interactions. Like other FXa inhibitors, edoxaban's exposure is affected by drugs that inhibit the P-glycoprotein transport protein. Edoxaban has a half-life of $8-10 \mathrm{~h}$; in a study of normal human volunteers, single doses of edoxaban 30 and $60 \mathrm{mg}$ suppressed thrombin generation for up to $24 \mathrm{~h}(16,17)$.

Studies have shown that the risk of bleeding with anticoagulant or antiplatelet therapy is higher in Asians than in Western patients; therefore, it is important to evaluate new anticoagulants in differ- 
ent ethnic groups (18). In addition, because Asian countries are participating in the large global phase III studies of edoxaban that are now ongoing, it was important to conduct a dose-finding study exclusively in Asian patients.

The primary objective of this study was to evaluate the incidence of all bleeding (major, clinically relevant non-major and minor) with two fixed dosages of edoxaban (30 mg qd or $60 \mathrm{mg} \mathrm{qd}$ ) compared with warfarin as active control in Asian patients with NVAF.

\section{Materials and methods}

\section{Study population}

Male or female patients aged 18-80 years, with NVAF (confirmed by abnormal electrocardiogram of AF twice within six months prior to randomisation) and with a $\mathrm{CHADS}_{2}$ index score (19) $\geq 1$ were eligible for the study. Exclusion criteria included: previous valve surgery, contraindication to anticoagulants, known bleeding disorder, conditions associated with high risk of bleeding (e.g. past history of major bleeding; uncontrolled hypertension; uncontrolled diabetes; haemorrhagic disorder; significant thrombocytopenia), ongoing treatment with an antiplatelet agent, AF secondary to other reversible disorders (e.g. thyrotoxicosis), acute coronary syndrome or revascularisation procedures, stroke, transient ischaemic attack, any major surgery within the previous 30 days, left ventricular aneurysm or atrial myxoma, impaired hepatic function (L-aspartate aminotransferase $\geq 2.0$ times the upper limit of normal [ULN], L-alanine aminotransferase $\geq 2.0$ times the ULN, alkaline phosphatase $>2.0$ times the ULN, total bilirubin $>2.0$ times the ULN), serum creatinine $\geq 1.5 \mathrm{mg} / \mathrm{dl}$, women of child-bearing potential without adequate contraception, pregnancy or lactation.

\section{Study design}

This was a randomised, parallel-group, multicentre, double-blind edoxaban and open-label warfarin study of two fixed doses of edoxaban with warfarin as active control conducted in four Asian countries (Taiwan, South Korea, Hong Kong and Singapore). The investigator, patients and sponsor were blinded to the dose of edoxaban, but not to the identity of edoxaban and warfarin. Patients were randomised to edoxaban $30 \mathrm{mg}$ qd, $60 \mathrm{mg}$ qd or warfarin dose adjusted to a target international normalised ratio (INR) of 2-3 in a 1:1:1 ratio via Fisher Automated Clinical Trials System (FACTS), and followed for three months. Block randomisation was done by FACTS; Cenduit produced the randomisation schedule, which was kept confidential until the end of the study. A patient who received $\geq 75 \%$ of the planned study drug was considered to be compliant. The study was conducted in accordance with the protocol, the principles set forth in the Declaration of Helsinki, International Conference on Harmonisation (ICH) for Good Clinical Practice (GCP), and all applicable local regulatory requirements.

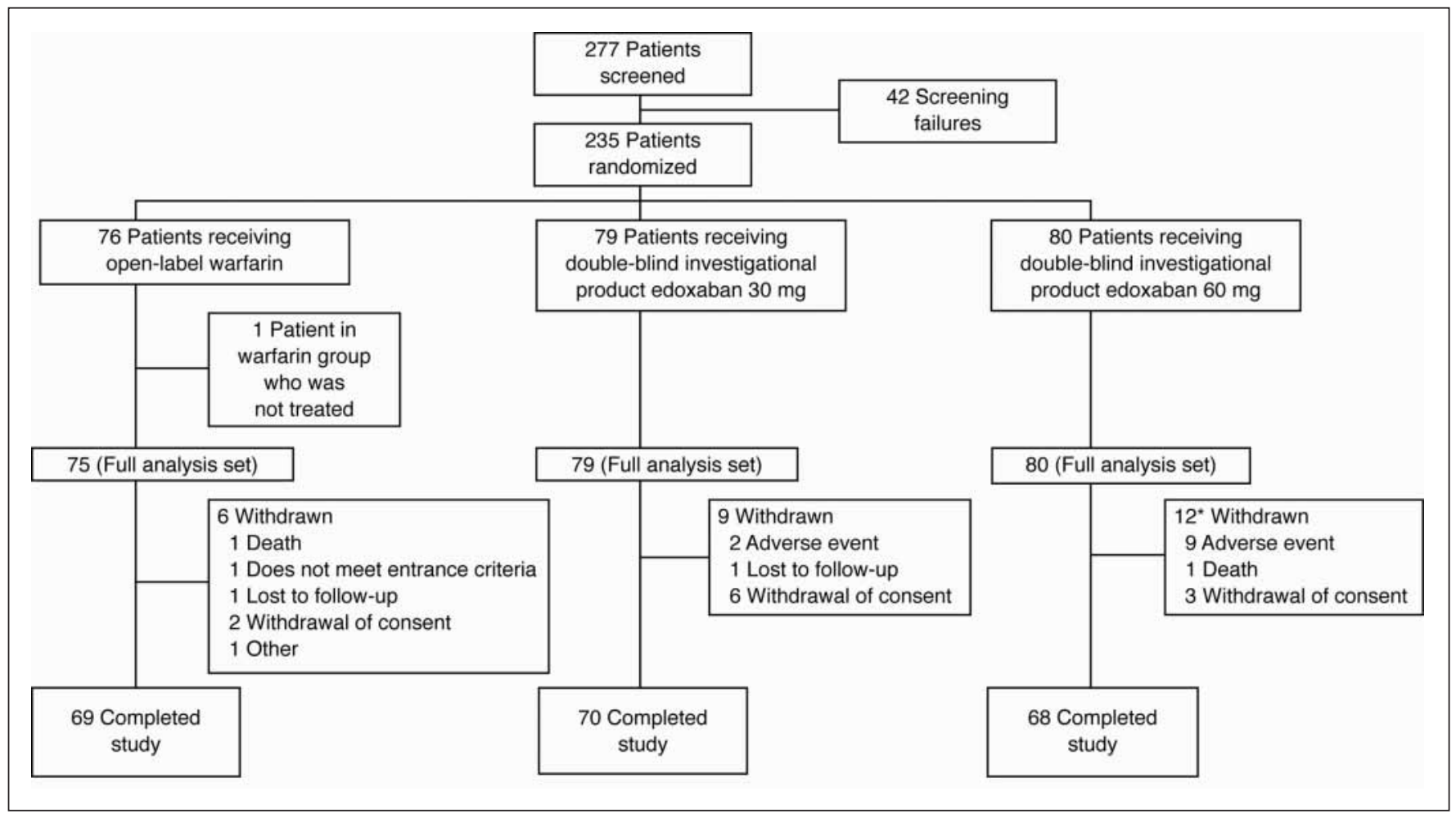

Figure 1: Patient disposition. *Patients may have withdrawn for more than one reason. 


\section{Study endpoints}

The primary study endpoint was the incidence of all bleeding events (major, clinically relevant non-major and minor) with two fixed dosages of edoxaban (30 mg qd or $60 \mathrm{mg}$ qd) in comparison with warfarin. Major bleeding was defined as overt if it was fatal, bleeding associated with $\geq 2 \mathrm{~g} / \mathrm{dl}$ drop in haemoglobin, transfusion $\geq 800 \mathrm{ml}$ of packed red blood cells or whole blood, and bleeding into a critical area or organ (retroperitoneal, intracranial, intraocular, intraspinal, intra-articular or pericardial or intramuscular with compartment syndrome). Clinically relevant non-major bleeding was defined as bleeding not meeting the criteria for major bleeding but resulting in discontinuation of study medication; spontaneous skin haematoma $\geq 25 \mathrm{~cm}^{2}$; spontaneous ear-nose-throat bleeding or gingival bleeding lasting $\geq 5$ minutes; macroscopic haematuria or urethral bleeding requiring medical attention; spontaneous gastrointestinal or rectal bleeding and any other bleeding event considered clinically significant by the investigator and the Clinical Events Committee (CEC). Minor bleeding was defined as bleeding not fulfilling the criteria for major or clinically relevant non-major bleeding and included macroscopic haematuria; occult haematuria $\geq 2+$; occult haematuria with microscopic $(\mathrm{RBC}) \geq 10$ /high power field; ecchymosis, epistaxis and gingival bleeding occurring without any external stimuli. Secondary safety variables were all adverse events (AEs) and laboratory variables. The secondary efficacy endpoint was incidence of major adverse cardiovascular (CV) events (MACE), consisting of stroke (ischaemic or haemorrhagic), systemic embolic event, myocardial infarction (MI), CV death and hospitalisation for any other cardiac condition. Also, effects on D-dimer, a biomarker of thrombus formation, were explored.
Table 1: Demographic and baseline characteristics.

\begin{tabular}{|c|c|c|c|c|}
\hline \multirow[t]{2}{*}{ Characteristics } & & \multicolumn{2}{|l|}{ Edoxaban } & \multirow{2}{*}{$\begin{array}{l}\text { Warfarin } \\
(\mathrm{n}=75)\end{array}$} \\
\hline & & $\begin{array}{l}30 \mathrm{mg} \\
(\mathrm{n}=79)\end{array}$ & $\begin{array}{l}60 \mathrm{mg} \\
(\mathrm{n}=80)\end{array}$ & \\
\hline \multirow[t]{2}{*}{ Age (years) } & Mean (SD) & $64.9(9.1)$ & $65.9(7.7)$ & $64.5(9.5)$ \\
\hline & $<60$ (n [\%]) & $15(19.0)$ & $18(22.5)$ & $21(28.0)$ \\
\hline $\operatorname{Sex}(n[\%])$ & Male & $51(64.6)$ & $55(68.8)$ & $47(62.7)$ \\
\hline \multirow[t]{2}{*}{ Body weight (kg) } & Mean (SD) & $70.5(11.6)$ & $71.5(12.1)$ & $68.1(12.1)$ \\
\hline & $\leq 60 \mathrm{~kg}(\%)$ & $15(19.0)$ & $16(20.0)$ & $20(26.7)$ \\
\hline \multirow[t]{5}{*}{ Presence of risk factors for embolism (n [\%]) } & Hypertension & $56(70.9)$ & $59(73.8)$ & $52(69.3)$ \\
\hline & Diabetes mellitus & $30(38.0)$ & $22(27.5)$ & $17(22.7)$ \\
\hline & $\begin{array}{l}\text { Congestive heart } \\
\text { failure }\end{array}$ & $18(22.8)$ & $25(31.3)$ & $24(32.0)$ \\
\hline & $\begin{array}{l}\text { History of TIA or } \\
\text { cerebral infarction }\end{array}$ & $21(26.6)$ & $19(23.8)$ & $17(22.7)$ \\
\hline & Age: $\geq 75$ years & $12(15.2)$ & $9(11.3)$ & $10(13.3)$ \\
\hline \multirow[t]{4}{*}{$\mathrm{CHADS}_{2}$ score } & $1(\mathrm{n}[\%])$ & $33(41.8)$ & $37(46.3)$ & $40(53.3)$ \\
\hline & 2 (n [\%]) & $24(30.4)$ & $21(26.3)$ & $18(24.0)$ \\
\hline & $3-6(n[\%])$ & $22(27.8)$ & $22(27.5)$ & $17(22.7)$ \\
\hline & mean (SD) & $2.0(1.10)$ & $1.9(1.03)$ & $1.8(1.10)$ \\
\hline Prior treatment with warfarin & Present (n [\%]) & $40(50.6)$ & $40(50.0)$ & $41(54.7)$ \\
\hline \multirow[t]{2}{*}{$\mathrm{CL}_{\mathrm{CR}}(\mathrm{ml} / \mathrm{min})$} & $<50(\mathrm{n}[\%])$ & $12(15.2)$ & $14(17.5)$ & $16(21.3)$ \\
\hline & $\geq 50(n[\%])$ & $67(84.8)$ & $66(82.5)$ & $59(78.7)$ \\
\hline \multirow[t]{2}{*}{ Concomitant use of aspirin } & Yes $(n[\%])$ & $34(43.0)$ & $33(41.3)$ & $26(34.7)$ \\
\hline & No (n[\%]) & $45(57.0)$ & $47(58.8)$ & $49(65.3)$ \\
\hline \multicolumn{5}{|l|}{ Liver function } \\
\hline AST (GOT) $\geq 3$ times the ULN & $\mathrm{n} / \mathrm{N}(\%)$ & $0 / 78(0.0)$ & $1 / 78(1.3)$ & $0 / 75(0.0)$ \\
\hline ALT (GPT) $\geq 3$ times the ULN & $\mathrm{n} / \mathrm{N}(\%)$ & $1 / 78(1.3)$ & $0 / 78(0.0)$ & $0 / 75(0.0)$ \\
\hline Total bilirubin $\geq 2$ times the ULN & $\mathrm{n} / \mathrm{N}(\%)$ & $4 / 78(5.1)$ & $4 / 78(5.1)$ & $1 / 75(1.3)$ \\
\hline $\begin{array}{l}\text { AST (GOT) or ALT (GPT) } \geq 3 \text { times the ULN } \\
\text { and total bilirubin } \geq 2 \text { times the ULN }\end{array}$ & $\mathrm{n} / \mathrm{N}(\%)$ & $0 / 78(0.0)$ & $1 / 78(1.3)$ & $0 / 75(0.0)$ \\
\hline \multicolumn{5}{|c|}{$\begin{array}{l}\text { Abbreviations: ALT (GPT): alanine aminotransferase (glutamine pyruvic transaminase); AST (GOT): aspartate } \\
\text { aminotransferase (glutamic oxaloacetic transaminase); } \text { CHADS}_{2} \text { : scoring system used to identify patients in } \\
\text { need of anticoagulation (congestive heart failure, hypertension, age, diabetes, previous stroke); } \mathrm{CL}_{\mathrm{CR}} \text { : creati- } \\
\text { nine clearance; SD: standard deviation; TIA: transient ischaemic attack; ULN: upper limit of normal. }\end{array}$} \\
\hline
\end{tabular}


Table 2: CHADS $_{2}$-VASc scores.

\begin{tabular}{|c|c|c|c|c|}
\hline \multicolumn{2}{|c|}{ Characteristics } & \multicolumn{2}{|c|}{ Edoxaban } & \multirow{2}{*}{$\begin{array}{l}\text { Warfarin } \\
(n=75)\end{array}$} \\
\hline & & $\begin{array}{l}30 \mathrm{mg} \\
(\mathrm{n}=79)\end{array}$ & $\begin{array}{l}60 \mathrm{mg} \\
(\mathrm{n}=80)\end{array}$ & \\
\hline \multirow{10}{*}{$\begin{array}{l}\text { CHADS }_{2} \text {-VASC } \\
\text { score }\end{array}$} & $0(\mathrm{n}[\%])$ & $0(0.0)$ & $0(0.0)$ & $0(0.0)$ \\
\hline & $1(n[\%])$ & $5(6.3)$ & $13(16.3)$ & $11(14.7)$ \\
\hline & $2(n[\%])$ & $23(29.1)$ & $17(21.3)$ & $17(22.7)$ \\
\hline & $3(n[\%])$ & $21(26.6)$ & $17(21.3)$ & $22(29.3)$ \\
\hline & $4(n[\%])$ & $17(21.5)$ & $24(30.0)$ & $10(13.3)$ \\
\hline & $5(n[\%])$ & $7(8.9)$ & $5(6.3)$ & $10(13.3)$ \\
\hline & $6(n[\%])$ & $4(5.1)$ & $3(3.8)$ & $3(4.0)$ \\
\hline & 7 (n[\%]) & $2(2.5)$ & $1(1.3)$ & $2(2.7)$ \\
\hline & $8-10(n[\%])$ & $0(0.0)$ & $0(0.0)$ & $0(0.0)$ \\
\hline & Mean (SD) & $3.2(1.40)$ & $3.1(1.40)$ & $3.1(1.51)$ \\
\hline
\end{tabular}

CHADS $_{2}$-VASc: The 2009 Birmingham Schema expressed as appoint-based scoring system (congestive heart failure/left ventricular dysfunction, hypertension, age $\geq 75$ years, diabetes mellitus, stroke/TIA/thromboembolism, vascular disease (prior myocardial infarction, peripheral artery disease, or aortic plaque), age 65-74 years, sex category (ie, female).

The independent CEC, which was blinded to study treatments, adjudicated all bleeding events and thromboembolic events (stroke, systemic embolic event, MI) during the study.

\section{Sample analysis}

Blood samples were collected for D-dimer (biomarker of thrombus formation) and pharmacodynamic (PD) variables on Day 1, and Weeks 4, 8, and 12, as well as at the 1- and 2-month follow-up visits for all patients. The lower limit of $\mathrm{D}$-dimer detection was 0.02 . The intra-assay and inter-assay variability (coefficient of variability) ranged from $0.78-2.19 \%$ and $2.85-3.56 \%$, respectively.
The samples for plasma concentrations of edoxaban were collected on Weeks 4 and 8. Blood samples for clinical chemistry, haematology and coagulation were taken during screening $(\leq 1$ month), treatment (Day 1, Weeks 2, 4 and 8), end of treatment (Week 12) and follow-up period (Months 1 and 2 post-last dose).

\section{Statistical analyses}

The sample size was determined based on the precision of the estimate of the difference in the incidence of all bleeding (major, clinically relevant non-major, and minor bleeding) between treatment groups. If the true incidence of either of these is $10 \%$, a sample size of 82 patients per treatment group would provide an estimate of the difference in incidence with precision of $20 \%$ (95\% confidence interval $[\mathrm{CI}]$ ). One hundred patients per treatment group were planned presuming a dropout rate of $20 \%$. However, a decision was made by the sponsor and the chairperson of the Independent Data Monitoring Committee to change the sample size based on re-evaluation and confirmation that 75 patients per group was acceptable for precise estimation of the incidence of bleeding events in this preliminary study of safety (CI of $20 \%$ for initial plan, CI of $20.7 \%$ for revised size). The safety analysis set comprised all patients who received at least one dose of study drug and had at least one post-dose safety assessment.

The primary analysis population for the efficacy endpoints was the full analysis set (FAS) defined as all the patients who received at least one dose of study drug and had at least one post-dose efficacy assessment. The PK analysis set was defined as all patients who were included in the FAS and had at least one plasma concentration data point. The PD analysis set was defined as all patients who were included in FAS and had one or more PD or biomarker data. The incidence of MACE and incidence of bleeding events was summarised by treatment group and 95\% CIs were determined based on the Score method. The differences in incidence between the two edoxaban groups and between each edoxaban group and

\begin{tabular}{|c|c|c|c|c|c|}
\hline \multirow[t]{2}{*}{ INR range } & \multicolumn{4}{|c|}{$\begin{array}{l}\text { Number }(\%) \text { of patients in the warfarin } \\
\text { group }\end{array}$} & \multirow{2}{*}{$\begin{array}{l}\text { Warfarin } \\
\text { Total of period (days) }(\%) \\
(\mathrm{N}=70)\end{array}$} \\
\hline & $\begin{array}{l}\text { Baseline } \\
(\mathrm{N}=70)\end{array}$ & $\begin{array}{l}\text { Day } 28 \\
(\mathrm{~N}=71)\end{array}$ & $\begin{array}{l}\text { Day } 56 \\
(\mathrm{~N}=70)\end{array}$ & $\begin{array}{l}\text { Day } 84 \\
(\mathrm{~N}=70)\end{array}$ & \\
\hline$<2.0$ & $\begin{array}{l}59 \\
(84.3 \%)\end{array}$ & $\begin{array}{l}39 \\
(54.9 \%)\end{array}$ & $\begin{array}{l}30 \\
(42.9 \%)\end{array}$ & $\begin{array}{l}31 \\
(44.3 \%)\end{array}$ & $\begin{array}{l}863.0 \\
(43.9 \%)\end{array}$ \\
\hline $\begin{array}{l}\geq 2.0 \text { to } \leq 3.0 \\
\text { (target) }\end{array}$ & $\begin{array}{l}10 \\
(14.3 \%)\end{array}$ & $\begin{array}{l}23 \\
(32.4 \%)\end{array}$ & $\begin{array}{l}30 \\
(42.9 \%)\end{array}$ & $\begin{array}{l}33 \\
(47.1 \%)\end{array}$ & $\begin{array}{l}886.0 \\
(45.1 \%)\end{array}$ \\
\hline$\geq 1.8$ to $\leq 3.2$ & $\begin{array}{l}15 \\
(21.4 \%)\end{array}$ & $\begin{array}{l}36 \\
(50.7 \%)\end{array}$ & $\begin{array}{l}36 \\
(51.4 \%)\end{array}$ & $\begin{array}{l}44 \\
(62.9 \%)\end{array}$ & $\begin{array}{l}1121.0 \\
(57.1 \%)\end{array}$ \\
\hline$>3.0$ & $\begin{array}{l}1 \\
(1.4 \%)\end{array}$ & $\begin{array}{l}9 \\
(12.7 \%)\end{array}$ & $\begin{array}{l}10 \\
(14.3 \%)\end{array}$ & $\begin{array}{l}6 \\
(8.6 \%)\end{array}$ & $\begin{array}{l}215.0 \\
(10.9 \%)\end{array}$ \\
\hline
\end{tabular}

Table 3: In-clinic INR data for warfarin treatment group.
INR: international normalised ratio. Percentages are based on number of patients at each visit. The period was calculated using the method of Rosendaal (22) using all available in-clinic INR results during Days 56-84. 
warfarin group were estimated with 95\% CIs for MACE and bleeding events $(20,21)$. Bleeding events, AEs and MACE were counted from the first dose to the next day of the last dose. The differences in the biomarkers of thrombin formation (D-dimer) between edoxaban doses and between each edoxaban dose and warfarin were estimated with 95\% CIs and the comparison between treatment groups was performed using a two-sample t-test. Descriptive statistics were used to summarise PK parameters.

Exploratory analysis was performed for the incidence of bleeding events reported by treatment group and analysed with 95\% CI based on the Wald method for the following subgroups: age, region, gender, body weight, risk factor, $\mathrm{CHADS}_{2}$ score, prior warfarin treatment, creatinine clearance, concomitant medication usage and aspirin with the presence/absence of dose adjustment factors. In addition, a logistic regression model was used to investigate the associations between incidence of bleeding and the factors.

\section{Results}

\section{Study population}

From October 20, 2007 (the first patient enrolled), until October 27, 2008 (the last patient completed), 235 patients were randomised to receive $30 \mathrm{mg}$ edoxaban $\mathrm{qd}(\mathrm{n}=79), 60 \mathrm{mg}$ edoxaban $\mathrm{qd}(\mathrm{n}=$ 80 ) or dose-adjusted (INR 2-3) warfarin $(\mathrm{n}=76)($ Fig. 1); 207 patients completed the study. A total of 234 patients were included in the FAS. The safety analysis set and FAS were identical.

Demographic and baseline characteristics of the 234 patients in the study were well balanced among the treatment groups ( Table 1). Mean $\mathrm{CHADS}_{2}$ scores (Table 1) and $\mathrm{CHADS}_{2}$-VASc scores ( Table 2) were comparable between the three groups. A total of $113(48.3 \%)$ patients were warfarin naïve. The overall compliance rate was $>96 \%$ in all of the treatment groups.
Table 4: Incidence of bleeding events.

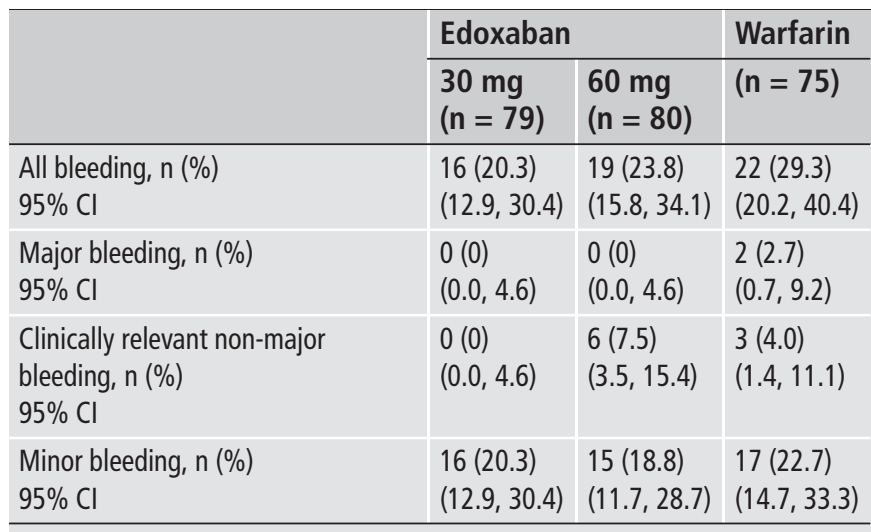

$\mathrm{Cl}$ : confidence interval. $95 \% \mathrm{Cl}$ based on the Score method.

Warfarin doses were adjusted based on INR values obtained by individual investigators at their local laboratories. In this study, $45.3 \%$ of patients were warfarin naïve at study entry in the warfarin group. As expected, the percentage of patients with INR values within the target range of 2-3 steadily increased from baseline. The time in therapeutic range, calculated using the method of Rosendaal (22), and excluding INR values in the first eight weeks of therapy, was $45.1 \%$ for an INR range of $2-3$ and $57.1 \%$ for an extended therapeutic INR range of 1.8-3.2 ( Table 3).

\section{Bleeding events}

The incidence of all bleeding events (major, clinically relevant non-major and minor) was $20.3 \%$ (16/79) (95\% CI: 12.9, 30.4) for edoxaban 30 mg qd, 23.8\% (19/80) (95\% CI: 15.8, 34.1) for edoxaban $60 \mathrm{mg}$ qd, and 29.3\% (22/75) (95\% CI: 20.2, 40.4) for the war-
Table 5: Incidence of bleeding events by body weight.

\begin{tabular}{|c|c|c|c|}
\hline & & \multicolumn{2}{|l|}{ Edoxaban } \\
\hline & & $\begin{array}{l}30 \mathrm{mg} \\
(\mathrm{n}=79)\end{array}$ & $\begin{array}{l}60 \mathrm{mg} \\
(\mathrm{n}=80)\end{array}$ \\
\hline \multirow[t]{2}{*}{ All bleeding } & $\begin{array}{l}\text { Incidence of event }(\leq 60 \mathrm{~kg})(\%) \\
95 \% \mathrm{Cl}\end{array}$ & $\begin{array}{l}40.0 \\
(19.8,64.3)\end{array}$ & $\begin{array}{l}31.3 \\
(14.2,55.6)\end{array}$ \\
\hline & $\begin{array}{l}\text { Incidence of event }(>60 \mathrm{~kg})(\%) \\
95 \% \mathrm{Cl} \text { for the difference }\end{array}$ & $\begin{array}{l}15.6 \\
(8.7,26.4)\end{array}$ & $\begin{array}{l}21.9 \\
(13.5,33.4)\end{array}$ \\
\hline \multirow[t]{2}{*}{$\begin{array}{l}\text { Major or clinical } \\
\text { relevant non-major bleeding }\end{array}$} & $\begin{array}{l}\text { Incidence of event }(\leq 60 \mathrm{~kg})(\%) \\
95 \% \mathrm{Cl}\end{array}$ & $\begin{array}{l}0.0 \\
(0.0,20.4)\end{array}$ & $\begin{array}{l}6.3 \\
(1.1,28.3)\end{array}$ \\
\hline & $\begin{array}{l}\text { Incidence of event }(>60 \mathrm{~kg})(\%) \\
95 \% \mathrm{Cl} \text { for the difference }\end{array}$ & $\begin{array}{l}0.0 \\
(0.0,5.7)\end{array}$ & $\begin{array}{l}7.8 \\
(3.4,17.0)\end{array}$ \\
\hline \multirow[t]{2}{*}{$\begin{array}{l}\text { All bleeding except for urinary } \\
\text { occult blood }\end{array}$} & $\begin{array}{l}\text { Incidence of event }(\leq 60 \mathrm{~kg})(\%) \\
95 \% \mathrm{Cl}\end{array}$ & $\begin{array}{l}0.0 \\
(0.0,20.4)\end{array}$ & $\begin{array}{l}6.3 \\
(1.1,28.3)\end{array}$ \\
\hline & $\begin{array}{l}\text { Incidence of event (>60 kg) }(\%) \\
95 \% \mathrm{Cl} \text { for the difference }\end{array}$ & $\begin{array}{l}6.3 \\
(2.5,15.0)\end{array}$ & $\begin{array}{l}10.9 \\
(5.4,20.9)\end{array}$ \\
\hline
\end{tabular}




\begin{tabular}{|c|c|c|c|}
\hline \multirow[t]{2}{*}{ Variable } & \multirow[t]{2}{*}{ P-value } & \multicolumn{2}{|c|}{ Odds ratio estimates } \\
\hline & & Estimate & $95 \% \mathrm{Cl}$ \\
\hline Gender (0: male, 1: female) & 0.571 & 1.25 & $0.57-2.75$ \\
\hline Body weight $(0:>50 \mathrm{~kg}, 1: \leq 50 \mathrm{~kg})$ & 0.326 & 4.13 & $0.24-69.94$ \\
\hline Body weight $(0:>55 \mathrm{~kg}, 1: \leq 55 \mathrm{~kg})$ & 0.952 & 1.05 & $0.21-5.34$ \\
\hline Body weight $(0:>60 \mathrm{~kg}, 1: \leq 60 \mathrm{~kg})$ & 0.048 & 2.38 & $1.01-5.62$ \\
\hline Body weight $(0:>65 \mathrm{~kg}, 1: \leq 65 \mathrm{~kg})$ & 0.194 & 1.66 & $0.77-3.56$ \\
\hline Risk factor - hypertension (0: no, 1: yes) & 0.879 & 0.94 & $0.41-2.16$ \\
\hline Risk factor - diabetes (0: no, 1: yes) & 0.013 & 0.28 & $0.10-0.76$ \\
\hline Risk factor - congestive heart failure (0: no, 1 : yes) & 0.801 & 0.90 & $0.38-2.12$ \\
\hline Risk factor - history of stroke or TIA (0: no, 1: yes) & 0.918 & 1.05 & $0.44-2.48$ \\
\hline Risk factor - age $>75$ years (0: no, 1 : yes) & 0.806 & 1.15 & $0.39-3.39$ \\
\hline $\mathrm{CHADS}_{2}$ score $(0: 1,1: 2-6)$ & 0.083 & 0.51 & $0.24-1.09$ \\
\hline $\mathrm{CHADS}_{2}$ score $(0: 1-2,1: 3-6)$ & 0.255 & 0.59 & $0.24-1.47$ \\
\hline $\mathrm{CHADS}_{2}$ score $(1,2,3,4,5,6)$ & 0.254 & 0.80 & $0.55-1.17$ \\
\hline Prior warfarin treatment (0: no, 1 : yes) & 0.540 & 0.79 & $0.37-1.68$ \\
\hline Creatinine clearance $(0: \geq 50 \mathrm{ml} / \mathrm{min}, 1:<50 \mathrm{ml} / \mathrm{min})$ & 0.696 & 0.81 & $0.28-2.33$ \\
\hline Concomitant usage - aspirin (0: no, 1: yes) & 0.436 & 0.43 & $0.05-3.58$ \\
\hline \multicolumn{4}{|c|}{$\begin{array}{l}\text { Abbreviations: } \mathrm{CHADS}_{2} \text { : scoring system used to identify patients in need of anticoagulation } \\
\text { (congestive heart failure, hypertension, age, diabetes, previous stroke); Cl: confidence interval; TIA: tran- } \\
\text { sient ischaemic attack. } 95 \% \mathrm{CL} \text { based on the Wald method. }\end{array}$} \\
\hline
\end{tabular}

Table 6: Logistic regression analysis for incidence of all bleeding events. farin group (Table 4). The differences (95\% CI) in the proportions of patients with any bleeding event between the warfarin group and the 30-mg or 60-mg edoxaban groups were $-9.1 \%$ $(-22.4 \%, 4.5 \%)$ and $-5.6 \%(-19.3 \%, 8.2 \%)$, respectively. Most patients experienced minor bleeding events. There were no major bleeding events in the edoxaban groups. In the warfarin group, two major bleeding events occurred, one retinal haemorrhage and one upper gastrointestinal haemorrhage, which were fatal. Clinically relevant non-major bleeding occurred in 7.5\% (6/80) (95\% CI: $3.5,15.4)$ of patients in the edoxaban $60-\mathrm{mg}$ group and $4.0 \%$ $(3 / 75)$ (95\% CI: $1.4,11.1)$ of patients in the warfarin group. No

Table 7: Summary of patients with AEs.

\begin{tabular}{|l|l|l|l|}
\hline & \multicolumn{2}{l}{ Edoxaban } & Warfarin \\
\cline { 2 - 4 } & $\begin{array}{l}\mathbf{3 0} \mathbf{~ m g} \\
(\mathbf{n}=\mathbf{7 9})\end{array}$ & $\begin{array}{l}\mathbf{6 0} \mathbf{~ m g} \\
\mathbf{( n = 8 0 )}\end{array}$ & $\mathbf{( n = 7 5 )}$ \\
\hline All AEs, $\mathrm{n}(\%)$ & $59(74.7 \%)$ & $59(73.8 \%)$ & $52(69.3 \%)$ \\
\hline Drug-related AEs, $\mathrm{n}(\%)$ & $17(21.5 \%)$ & $23(28.8 \%)$ & $25(33.3 \%)$ \\
\hline SAEs, $\mathrm{n}(\%)$ & $2(2.5 \%)$ & $5(6.3 \%)$ & $4(5.3 \%)$ \\
\hline Drug-related SAEs, $\mathrm{n}(\%)$ & $0(0.0 \%)$ & $1(1.3 \%)$ & $1(1.3 \%)$ \\
\hline $\begin{array}{l}\text { AEs leading to study drug } \\
\text { discontinuation permanently, } \mathrm{n}(\%)\end{array}$ & $3(3.8 \%)$ & $9(11.3 \%)$ & $2(2.7 \%)$ \\
\hline
\end{tabular}

Abbreviations: AE: adverse event; SAE: serious adverse event. Adverse event period is limited to the range from the time of first dose to the next day of the last dose. Adverse events leading to study drug discontinuation permanently: The events with study drug actions taken as permanent discontinuation. clinically relevant non-major bleeding was observed in the edoxaban 30-mg group. There were no statistically significant differences between the edoxaban dosing groups versus warfarin or between edoxaban $30 \mathrm{mg}$ versus edoxaban $60 \mathrm{mg}$ for all bleeding, major bleeding, clinically relevant non-major bleeding or minor bleeding, although the incidence of bleedings events in these groups was low.

The incidence of all bleeding events in the subgroup of patients with body weight $\leq 60 \mathrm{~kg}$ was higher than that in the subgroup of those weighing > $60 \mathrm{~kg}$ ( Table 5); the bleeding rate was $40.0 \%$ (95\% CI: 19.8, 64.3) and 15.6\% (95\% CI: 8.7,26.4) in the edoxaban $30-\mathrm{mg}$ group for $\leq 60 \mathrm{~kg}$ and $>60 \mathrm{~kg}$, respectively. In the edoxaban 60 -mg group, the incidence of all bleeding was 31.3\% (95\% CI: $14.2,55.6)$ and $21.9 \%$ (95\% CI: $13.5,33.4)$ for $\leq 60 \mathrm{~kg}$ and $>60 \mathrm{~kg}$, respectively. Analysis of other factors including creatinine clearance, age, gender, region, concomitant diseases, prior warfarin use, concomitant medications, and $\mathrm{CHADS}_{2}$ score did not yield meaningful results. The odds ratio of all bleeding events for body weight $\leq 60 \mathrm{~kg}$ vs. $>60 \mathrm{~kg}$ estimated by logistic regression analysis was 2.38 $(1.01,5.62)(\mathrm{p}=0.048)(-$ Table 6$)$, suggesting that body weight may influence the incidence of bleeding events in both edoxaban groups.

\section{Adverse events}

A summary of patients with AEs is shown in Table 7. The incidence of study drug-related AEs was $21.5 \%$ (17/79) in the edox- 
Figure 2: Summary of edoxaban plasma concentration.

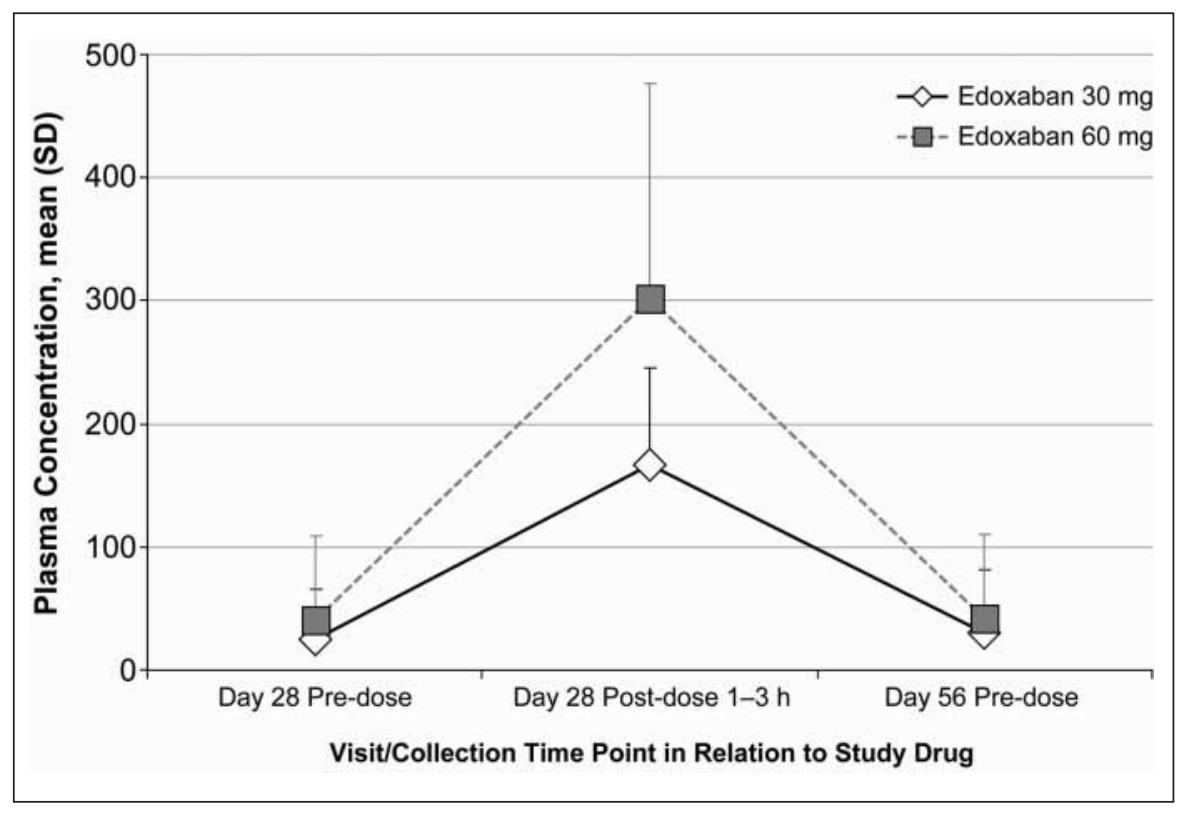

aban 30 -mg group, $28.8 \%$ (23/80) in the edoxaban 60 -mg group and $33.3 \%(25 / 75)$ in the warfarin group. The most commonly reported study drug-related AEs were blood urine present $(6.3 \%$, $10.0 \%$ and $6.7 \%)$, gingival bleeding $(2.5 \%, 6.3 \%$ and $0.0 \%)$ and haematuria $(7.6 \%, 6.3 \%$ and $10.7 \%)$ for edoxaban $30 \mathrm{mg}$, edoxaban $60 \mathrm{mg}$ and warfarin, respectively. The majority of drug-related AEs were mild to moderate in severity. Two serious AEs considered to be drug-related were observed, one each in the edoxaban 60 -mg group (gingival bleeding) and the warfarin group (upper gastrointestinal haemorrhage). The gingival bleeding resolved, whereas the upper gastrointestinal haemorrhage was fatal. There were no clinically significant changes in the mean values of any laboratory tests and no clinically relevant differences between the treatment groups.

\section{MACE}

MACE occurred in 2.5\% (2/79) of patients in the edoxaban 30-mg group, $3.8 \%(3 / 80)$ in the edoxaban $60-\mathrm{mg}$ group and $1.3 \%(1 / 75)$ in the warfarin group. Of these events, one MACE of CV death occurred in the edoxaban 60-mg group as a result of heart failure 13 days after the patient had prematurely stopped the study drug; this event was considered unrelated to the study drug by the investigator. All other MACE were hospitalisations for other cardiac conditions (exertional dyspnea, congestive heart failure or left-sided heart failure, angina pectoris), and were considered to be unrelated to the study drug by the investigator (two patients each in the edoxaban 30-mg and 60-mg groups; one patient in the warfarin group). No thromboembolic events occurred based on the adjudication of the CEC.

\section{PK and biomarker parameters}

The plasma concentrations of edoxaban were evaluated in the PK analysis set (edoxaban $30 \mathrm{mg}, \mathrm{n}=60$; edoxaban $60 \mathrm{mg}, \mathrm{n}=66$ ). The mean plasma concentrations of edoxaban in the edoxaban $60-\mathrm{mg}$ group were approximately two-fold higher than those in the edoxaban 30-mg group, both at trough and between 1 and $3 \mathrm{~h}$ after administration ( Fig. 2).

The effects on D-dimer, a biomarker of thrombus formation, were evaluated using the PD analysis set (edoxaban $30 \mathrm{mg}, \mathrm{n}=79$; edoxaban $60 \mathrm{mg}, \mathrm{n}=80$; warfarin, $n=75$ ). In the warfarin naïve patients, D-dimer was decreased in all treatment groups, but to a greater degree in the edoxaban 60-mg and warfarin groups ( Fig. $3 \mathrm{~A})$. D-dimer was already suppressed in the warfarin experienced patients and started and remained low following treatment with different doses of edoxaban ( Fig. 3B).

\section{Discussion}

The results of this study showed that oral doses of the novel, direct FXa inhibitor edoxaban $30 \mathrm{mg}$ qd and $60 \mathrm{mg}$ qd were safe and well tolerated and were associated with a trend to lower incidence of bleeding compared with warfarin in Asian patients with NVAF and a $\mathrm{CHADS}_{2}$ score $\geq 1$ when administered for three months, although the difference was not statistically significant. There were no major bleeding events in the edoxaban-treated patients compared with two major bleeding events in the warfarin group, including a fatal upper gastrointestinal bleed. The majority of the bleeding events in this study were minor. As the number of bleeding events was generally low across all groups, no significant difference in bleeding incidence was observed between the edoxaban 30-mg and 60-mg 

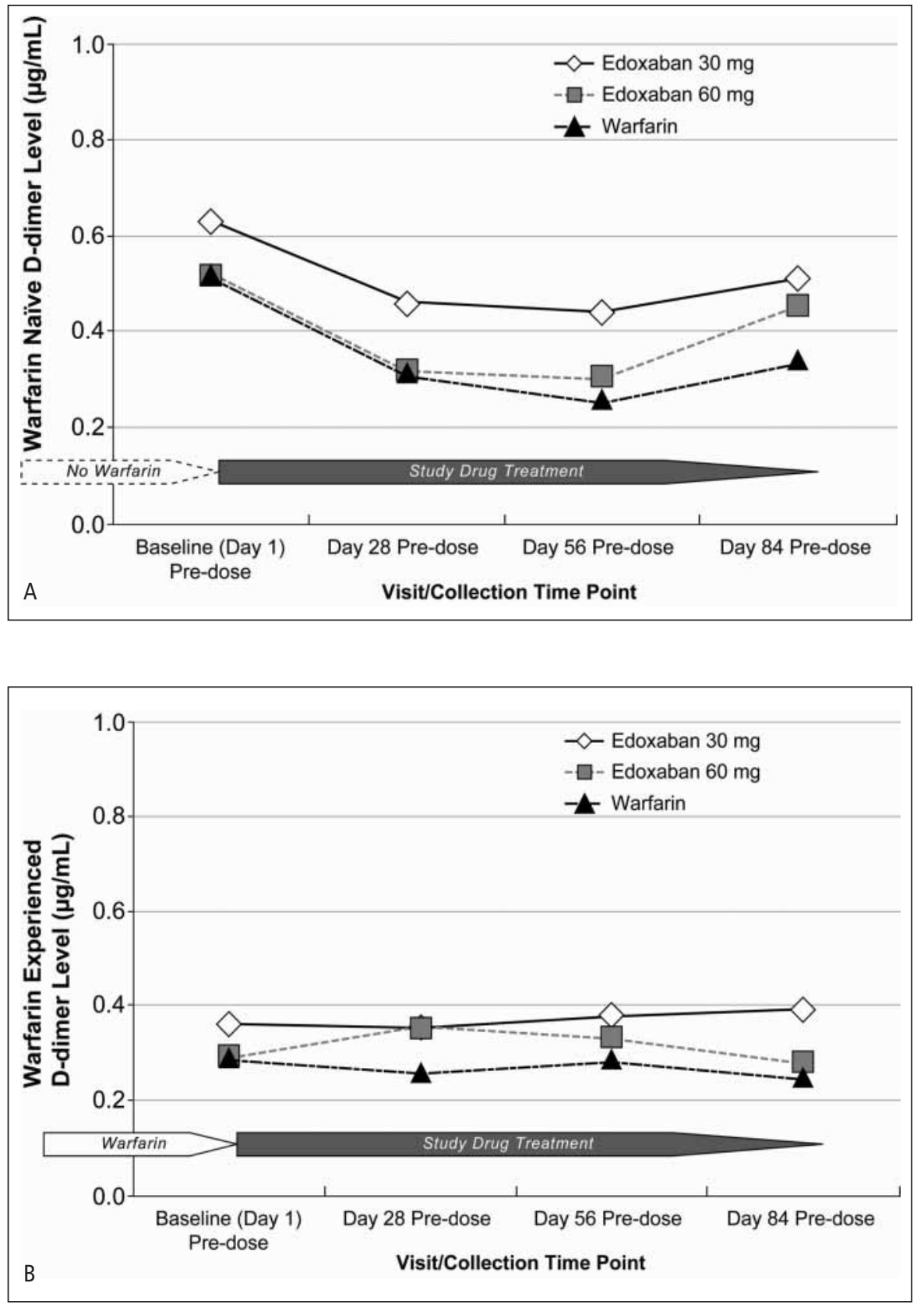

Figure 3: D-dimer levels in warfarin naïve patients $(A)$ and warfarin experienced patients (B). dose groups. The low incidence of bleeding events suggests that the study may have been underpowered to demonstrate a statistically significant difference among groups.

The logistic regression analysis, with bleeding events as the objective variable, and subgroup analysis of bleeding events by demographic factors, suggested body weight might affect the incidence of bleeding events in the edoxaban groups. The incidence of all bleeding events in the subgroup of patients with body weight $\leq 60$ $\mathrm{kg}$ was higher than that in the subgroup of those with body weight $>60 \mathrm{~kg}$ in both edoxaban groups (30 mg and $60 \mathrm{mg}$ ), suggesting that dose adjustment may be needed in patients with low body weight $(\leq 60 \mathrm{~kg})$. However, the influence of body weight on major or clinically relevant non-major bleeding events could not be assessed because of the small number of events. Although no diabetes was identified on logistic regression as a risk for all bleeding, the meaning of this finding is uncertain as it has not been found in similar studies (23).

There were no thromboembolic events according to the adjudication of the CEC observed in this study and no MACE related to the study drug. In warfarin naïve patients, D-dimer levels were suppressed in both edoxaban 30-mg and 60-mg groups. In addition, the extent of D-dimer suppression was similar in the edoxaban 60-mg and warfarin groups. 


\section{What is known about this topic?}

- Guidelines recommend prophylaxis with dose-adjusted vitamin $\mathrm{K}$ antagonists (VKAs) for stroke prevention in patients with nonvalvular atrial fibrillation.

- Limitations of VKAs are unpredictable pharmacokinetics and pharmacodynamics, drug and food interactions, and genetic variability in response, all of which necessitate frequent monitoring and dose adjustments.

\section{What does this paper add?}

- Edoxaban, an oral factor Xa inhibitor, is in development for stroke prevention in atrial fibrillation and treatment for venous thromboembolism.

- This phase II study of edoxaban $30 \mathrm{mg}$ and $60 \mathrm{mg}$ qd in Asian patients with non-valvular atrial fibrillation showed a trend for reduced incidence of all bleeding compared with dose-adjusted warfarin, confirming edoxaban's safety for a phase III study (ENGAGE AF-TIMI 48).

- This study suggests that dose adjustment of edoxaban may be required in patients with low body weight $(\leq 60 \mathrm{~kg})$.

Considering the risk of bleeding with warfarin therapy has been shown to be higher in Asian patients than in Western patients (18), the effect of new anticoagulants in different ethnic groups must be carefully examined. The safety of edoxaban in AF patients has been previously evaluated in two studies $(23,24)$ as well as the current study to confirm its use in a phase III study. In a multinational study of 1146 patients with a $\mathrm{CHADS}_{2}$ index score $\geq 2$ randomised to double-blind edoxaban $30 \mathrm{mg}$ qd, $60 \mathrm{mg}$ qd, $30 \mathrm{mg}$ bid or $60 \mathrm{mg}$ bid, or open-label warfarin (INR 2-3) for three months, edoxaban qd regimens had similar or less bleeding than warfarin, whereas the bid regimens had significantly greater bleeding than warfarin (24). In another study conducted in Japan of 525 patients with a $\mathrm{CHADS}_{2}$ index score $\geq 1$ randomised to three dose levels of edoxaban (30 mg qd, $45 \mathrm{mg}$ qd, and $60 \mathrm{mg}$ qd) or warfarin as an active control (INR 2-3) for three months, there was no difference in the mean incidence of all bleeding for edoxaban across the dose range, and a logistic regression analysis suggested that low body weight $(\leq 60 \mathrm{~kg})$ is an important covariate for bleeding (23).

This study confirmed the safety and tolerability of edoxaban (30 mg qd and $60 \mathrm{mg} \mathrm{qd}$ ) in Asian patients and found the same risk factor (i.e. body weight $\leq 60 \mathrm{~kg}$ ) for bleeding events as in the Japanese study (23).

From these three studies, the bleeding risk of edoxaban $30 \mathrm{mg}$ qd or $60 \mathrm{mg}$ qd was lower or similar to that of warfarin, provided that dose adjustments are made in patients with a body weight $\leq 60$ $\mathrm{kg}$. Body weight was not found to be a risk factor for bleeding in the Western study (24), likely because of the small number of patients with low body weight randomised to each treatment group. Because phase II studies conducted in Asian-only populations are still rare, this study is very meaningful to define the safety of edoxaban in Asian patients before conducting the global phase III study.

The main limitation of this study was that formal statistical analysis of safety and efficacy could not be conducted due to the small sample size. The large multinational, phase III trial, ENGAGE AF-TIMI 48, is underway to further evaluate the safety and efficacy of edoxaban $30 \mathrm{mg}$ and $60 \mathrm{mg}$ in AF patients (25).

In conclusion, when administered at doses of $30 \mathrm{mg}$ and $60 \mathrm{mg}$ qd in Asian patients with NVAF, the incidence of all bleeding events showed a trend for reduced incidence of bleeding with edoxaban compared with warfarin. Low body weight $(\leq 60 \mathrm{~kg})$ may affect the incidence of bleeding events with edoxaban. An ongoing multinational, phase III trial, ENGAGE AF-TIMI 48, has been designed based on the above results.

\section{Acknowledgements}

The authors would like to acknowledge members of the Efficacy and Safety Monitoring Board Independent Data Monitoring Committee: Prof. Jen-Pei Liu (Chairperson), Dr. Wei-Hsian Yin, and Dr. Christopher Chen Li Hsian; as well as members of the Clinical Events Committee: Masatoshi Kawana, MD, PhD, Yasuhiro Hasegawa, $\mathrm{MD}, \mathrm{PhD}$, and Yoko Kawai, $\mathrm{MD}, \mathrm{PhD}$; the sponsor representatives: Yasuhiro Nishikawa, MD, $\mathrm{PhD}$ (medical expert), Koji Fujii, PhD (Project manager); Atsushi Nonogaki (Study Leader), and Toshiyuki Sato (Statistician), and Takeshi Yamashita, $\mathrm{MD}, \mathrm{PhD}$ (medical expert) for study oversight. The authors would also like to acknowledge writing assistance provided by Sameena Azmi, PhD, as well as editorial assistance by Quintiles Medical Communications, Parsippany, NJ, USA, which was funded by Daiichi Sankyo Co., Ltd.

\section{Investigators who recruited patients}

Hong Kong: H.F.Tse, C.M. Yu; Korea: N. Chung, H.K. Jeon, S.J. Rim, B.W. Yoon, J.Y. Yang, W.S. Chung, K.B. Seung, D.J. Choi, C. Kim; Singapore: S. Vijay, C.Y. Lee; Taiwan: C.Y. Fang, C.C. Cheng, C.D. Tseng, H.I. Yeh, L.M. Lien, C.L. Han, W.T. Lai, S.A. Chen, C.C. Chen, Y.L. Ko, C.H. Huang, T.H. Lee.

\section{References}

1. Albers GW, Dalen JE, Laupacis A, et al. Antithrombotic therapy in atrial fibrillation. Chest 2001; 119 (1 Suppl): 194S-206S.

2. Go AS, Hylek EM, Phillips KA, et al. Prevalence of diagnosed atrial fibrillation in adults: national implications for rhythm management and stroke prevention: the AnTicoagulation and Risk Factors in Atrial Fibrillation (ATRIA) Study. J Am Med Assoc 2001; 285: 2370-2375.

3. Benjamin EJ, Wolf PA, D'Agostino RB, et al. Impact of atrial fibrillation on the risk of death: the Framingham Heart Study. Circulation 1998; 98: 946-952.

4. Flegel KM, Shipley MJ, Rose G. Risk of stroke in non-rheumatic atrial fibrillation. Lancet 1987; 1: 526-529.

5. Risk factors for stroke and efficacy of antithrombotic therapy in atrial fibrillation. Analysis of pooled data from five randomized controlled trials. Arch Intern Med 1994; 154: 1449-1457.

6. Hart RG, Benavente O, McBride R, et al. Antithrombotic therapy to prevent stroke in patients with atrial fibrillation: a meta-analysis. Ann Intern Med 1999; 131: 492-501.

7. Thromboembolic prophylaxis in 3575 hospitalized patients with atrial fibrillation. The Clinical Quality Improvement Network (CQIN) Investigators. Can J Cardiol 1998; 14: 695-702. 
8. Waldo AL, Becker RC, Tapson VF, et al. Hospitalized patients with atrial fibrillation and a high risk of stroke are not being provided with adequate anticoagulation. J Am Coll Cardiol 2005; 46: 1729-1736.

9. Go AS, Hylek EM, Borowsky LH, et al. Warfarin use among ambulatory patient with nonvalvular atrial fibrillation: the anticoagulation and risk factors in atrial fibrillation (ATRIA) study. Ann Intern Med 1999; 131: 927-934.

10. Hylek EM, D'Antonio J, Evans-Molina C, et al. Translating the results of randomized trials into clinical practice: the challenge of warfarin candidacy among hospitalized elderly patients with atrial fibrillation. Stroke 2006; 37: 1075-1080.

11. Birman-Deych E, Radford MJ, Nilasena DS, et al. Use and effectiveness of warfarin in Medicare beneficiaries with atrial fibrillation. Stroke 2006; 37: 1070-1074.

12. Friberg L, Hammar N, Ringh M, et al. Stroke prophylaxis in atrial fibrillation: who gets it and who does not? Report from the Stockholm Cohort-study on Atrial Fibrillation (SCAF-study). Eur Heart J 2006; 27: 1954-1964.

13. Ingelgard A, Hollowell J, Reddy $\mathrm{P}$, et al. What are the barriers to warfarin use in at rial fibrillation?: Development of a questionnaire. J Thromb Thrombolysis 2006; 21: 257-265.

14. Gattellari M, Worthington J, Zwar N, et al. Barriers to the use of anticoagulation for nonvalvular atrial fibrillation: a representative survey of Australian family physicians. Stroke 2008; 39: 227-230.

15. Fuster V, Ryden LE, Cannom DS, et al. ACC/AHA/ESC 2006 guidelines for the management of patients with atrial fibrillation--executive summary: a report of the American College of Cardiology/American Heart Association Task Force on Practice Guidelines and the European Society of Cardiology Committee for Practice Guidelines (Writing Committee to Revise the 2001 Guidelines for the Management of Patients With Atrial Fibrillation). J Am Coll Cardiol 2006; 48: 854-906.

16. Ogata K, Mendell-Harary J, Tachibana M, et al. Clinical safety, tolerability, pharmacokinetics, and pharmacodynamics of the novel factor Xa inhibitor edoxaban in healthy volunteers. J Clin Pharmacol 2010; 50: 743-753.
17. Samama MM, Wolzt M, Ogata K, Mendell J, Kunitada S. Effect of edoxaban (DU-176b) on thrombin generation and platelet activation in shed and venous blood with fondaparinux as active comparator. Eur Heart J 2009; 30: 331 (Poster P2105).

18. Suzuki S, Yamashita T, Kato T, et al. Incidence of major bleeding complication of warfarin therapy in Japanese patients with atrial fibrillation. Circ J 2007; 71: 761-765.

19. Gage BF, Waterman AD, Shannon W, et al. Validation of clinical classification schemes for predicting stroke: results from the National Registry of Atrial Fibrillation. J Am Med Assoc 2001; 285: 2864-2870.

20. Newcombe RG. Two-sided confidence intervals for the single proportion: comparison of seven methods. Stat Med 1998; 17: 857-872.

21. Newcombe RG. Interval estimation for the difference between independent proportions: comparison of eleven methods. Stat Med 1998; 17: 873-890.

22. Rosendaal FR, Cannegieter SC, van der Meer FJ, et al. A method to determine the optimal intensity of oral anticoagulant therapy. Thromb Haemost 1993; 69: 236-239.

23. Yasaka M, Inoue H, Kawai Y, et al. Randomized, parallel group, warfarin control, multicenter phase II study evaluating safety of DU-176b in Japanese subjects with non-valvular atrial fibrillation (NVAF). Boston, MA: XXII Congress of The International Society on Thrombosis and Haemostasis (ISTH); July 11-16, 2009. J Thromb Haemost 2009; 7: 376 (Abstract).

24. Weitz JI, Connolly SJ, Patel I, et al. Randomised, parallel-group, multicentre, multinational phase 2 study comparing edoxaban, an oral factor Xa inhibitor, with warfarin for stroke prevention in patients with atrial fibrillation. Thromb Haemost 2010; 104: 633-641.

25. Daiichi Sankyo I, TIMI Study Group. Global Study to Assess the Safety and Effectiveness of DU-176b vs Standard Practice of Dosing With Warfarin in Patients With Atrial Fibrillation (EngageAFTIMI48). Clinicaltrials.gov, US National Institutes of Health. Updated November 19, 2009. http://www.clinicaltrials.gov/ ct2/show/NCT00781391?term=00781391\&rank=1. Accessed December 3, 2009. 